\title{
Cages with Low-Valent Elements of Main Group IV -Heavy Congeners of Isocyanide (Alkylisocyanide) and Carbon Monoxide
}

Polycyclic or cage-like compounds, which contain formula units such as $\left(\mathrm{GeN}^{\prime} \mathrm{Bu}\right),\left(\mathrm{SnN} \mathrm{N}^{\prime} \mathrm{Bu}\right)$ or $(\mathrm{SnO})$ or multiples of them, can be synthesized by a general procedure. A critical look is taken at the existence of these species as transient intermediates in certain reactions. Both chemical and structural information are considered.

\section{INTRODUCTION}

There are two stable, commonly known types of compounds in which the element carbon is in a special binding situation. In these compounds carbon uses only two of the four valence electrons for binding - thus two electrons form a lone pair: these are carbon monoxide and organic isocyanides. As $\pi$-bonds are very prominent in the chemistry of carbon, the following Lewis formulas may readily be written, considering an electron octet at the carbon atom:

$$
: \stackrel{-}{\mathbf{C}} \equiv \stackrel{+}{\mathrm{O}}: \quad: \overline{\mathrm{C}} \equiv \stackrel{+}{\mathrm{N}}-\mathbf{R}
$$

The formal charges on the elements result from electron donation from the oxygen and nitrogen atom, respectively, into the vacant outer-shell orbital of carbon. As may be concluded from the formulas, the two compounds can be classified as molecules and exist as gas (CO) or as a liquid (RNC) at ambient temperature. 
Compounds of the same stoichiometry are known for the heavier congeners of carbon, i.e., silicon, germanium, tin, and lead, but their properties are completely different from those of the carbon compounds. In the oxygen-containing series $\mathrm{SiO}, \mathrm{GeO}, \mathrm{SnO}$ and $\mathrm{PbO}$, the compounds are solids at ordinary temperatures' ( $\mathrm{SiO}$ is not structurally fully characterized), in which the heavy atoms are coordinated by the oxygen atoms in a way that is typical for solid state structures. From a molecular point of view, they may be characterized as threedimensional polymers. Extreme conditions are needed to prepare molecules: at high temperatures $\left(>1300^{\circ} \mathrm{C}\right)$ and low pressure the diatomic SiO has been observed spectroscopically. ${ }^{2}$

The great discrepancy in the structures and the chemistry of SiO, $\mathrm{GeO}, \mathrm{SnO}$ and $\mathrm{PbO}$ compared to $\mathrm{CO}$ (and the same is true for the isocyanide series, although not so much work has been done in this field) may be explained by the following reasoning:

When going down the periodic table from $\mathrm{C}$ to $\mathrm{Pb}$, the stability of $\pi$-bonding becomes less and the oligomer with single bonding is more stable than the monomer with $\pi$-bonding.

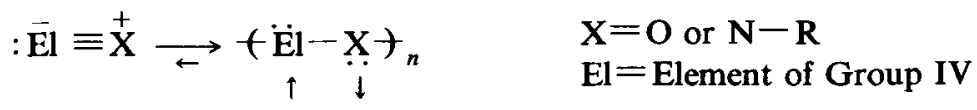

At the same time for the three mesomeric forms, which can be formulated for a compound ElX, type III should be increasingly favored as the electronegativity decreases from $\mathrm{C}$ to $\mathrm{Pb}$.

$$
\begin{aligned}
& \overline{\mathrm{El}} \equiv \stackrel{+}{\mathrm{X}} \leftrightarrow: \mathrm{El}=\ddot{\mathrm{X}} \leftrightarrow: \stackrel{+}{\mathrm{E} l}-\ddot{\mathrm{X}}^{-} \quad \mathrm{X}=\text { O or } \mathrm{N}-\mathrm{R} \\
& \text { I II III } \quad \mathrm{El}=\text { Element of Group IV }
\end{aligned}
$$

As the polarity of the bond within III is very high and the groupIV element is deprived of electrons, III should quickly oligomerize or polymerize.

It is not understandable from these models that ElX exclusively forms a monomeric molecule, as in the case of $\mathrm{El}=\mathrm{C}$, or a polymeric solid, when $\mathrm{El} \neq \mathrm{C}$. In addition to these two extreme cases, a number of oligomers of ElX should exist, which might be cyclic or polycyclic. The first representatives of this type were only found in $1979 .{ }^{3}$ 
In this Comment we introduce the chemistry of these oligomeric "congeners" of carbon monoxide and isocyanides and look critically at the question of the existence of an intermediate monomer ElX. In addition to chemical, a great deal of structural information will be used to answer this question.

\section{SYNTHESES OF POLYCYCLES AND CAGES CONTAINING Ge(II), Sn(II), AND Pb(II) BONDED TO NITROGEN OR OXYGEN}

\subsection{The Basic Reactions}

The four-membered cycles $1,{ }^{4} 2^{5}$ and $3,{ }^{4}$ which contain the low-valent elements $\mathrm{Ge}$ (II), $\mathrm{Sn}$ (II) and $\mathrm{Pb}$ (II), can be treated with hydrogen compounds of nitrogen and oxygen, such as primary amines $\mathrm{R}-\mathrm{NH}_{2}{ }^{3}$ or water $\left(\mathrm{H}_{2} \mathrm{O}\right)^{6}$ (Eqs. (1) and (2)). In each case the ring compounds are decomposed into the dimethylbis(amino)silane 4 by hydrogen transfer to the nitrogen atoms. The low-valent element is detached from the ring, bound to the attacking nitrogen or oxygen atom and included into a polycyclic compound which can be the oligomeric tetramer of ElN-R as in Eq. (1)..$^{3,4,6,7}$

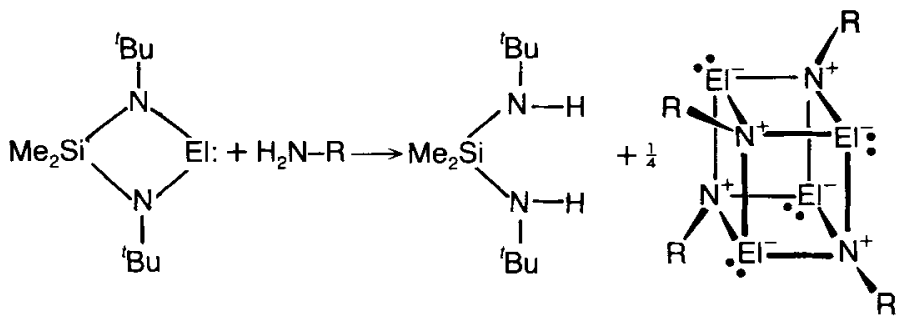

4

$$
\begin{gathered}
5(E l=G e), \quad 6(E l=S n) \\
7(E l=P b)
\end{gathered}
$$

$$
\mathrm{El}=\mathrm{Ge}(1), \mathrm{Sn}(2), \mathrm{Pb}(3) \quad \mathrm{R}=\mathrm{Me}_{2} \mathrm{CH}-, \mathrm{Me}_{2} \mathrm{~N}-, \mathrm{Ph}-\mathrm{CH}_{2}-\text {, etc. }
$$




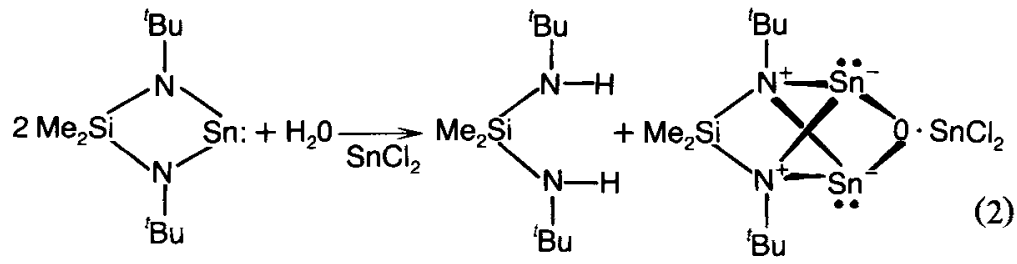

8

The difference between reaction (1) and (2) is that in the first case the starting ring compound does not interfere with any of the reaction products, whereas it does in the second case. In fact, it can be shown that this interference is dependent on the kind of base which attacks the Lewis acids 1,2 and $3^{4}$ : therefore a compound structurally equal to 8 is formed when isopropylamine in (1) is replaced by tert-butylamine (Eq. (3)). ${ }^{4}$

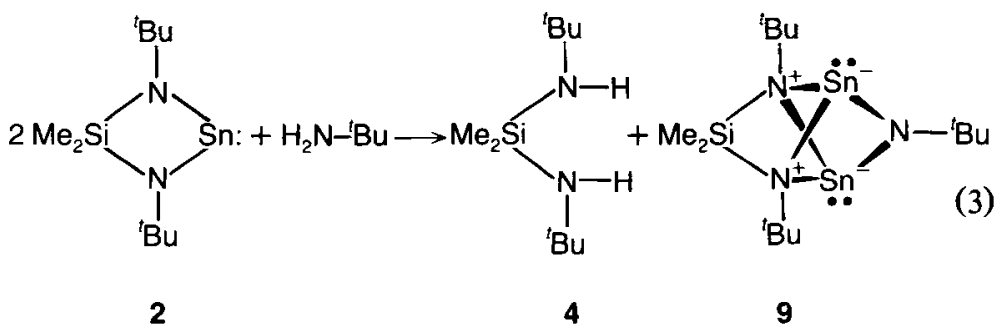

Not only do bulky substituents on the nitrogen atoms alter the reaction path, as in the last example, but the reaction path is also determined by the molar ratio of the reactants $s^{3,4}$ and the nature of the unsaturated compound 1,2 , and $3^{4}$; e.g., the compounds 10 and 11 are formed, when the molar ratio of the amine and the ring compound in (3) is $4: 3$ (the same is true when 1 reacts instead of 2).3,4

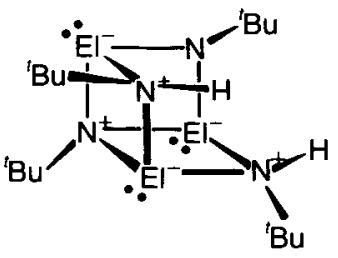

$10(E I=G e), \quad 11(E I=S n)$ 
$\mathrm{X}$-ray structure determinations of $6,{ }^{8} 8,{ }^{6}$ and $11^{9}$ have clearly demonstrated the cage-shaped structures of the compounds. Chemical reactions can be performed in order to modify their composition. Without going into details, the following compounds 12 and 13 are listed, which are all derived from a cubane-like skeleton. ${ }^{4,10}$

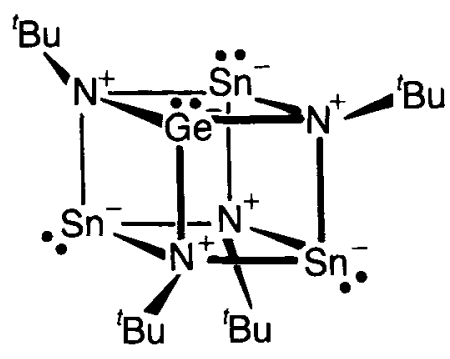

12

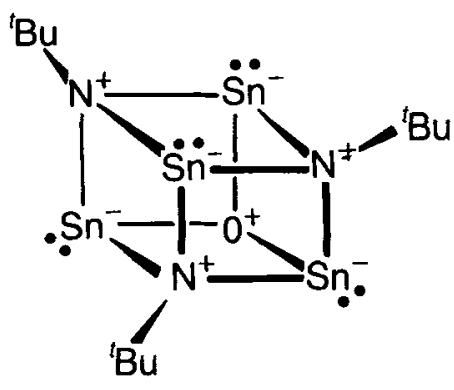

13

\subsection{The Hypothetical Reaction Path}

Considering the results described above, one is confronted with the question whether a common reaction mechanism can be attributed to the different reactions. The main point seems to be: Does a transient compound "GeN-R", "SnN-R" or "SnO" exist, which can be regarded as a congener of isocyanide or carbon monoxide?

To answer these questions, we have looked at the starting reaction of the diazastannylene $\mathbf{2}$ with tert-butylamine more closely. Without doubt the first reactive intermediate in this reaction is the Lewis acidbase adduct 14 (Eq. (4)). ${ }^{11}$

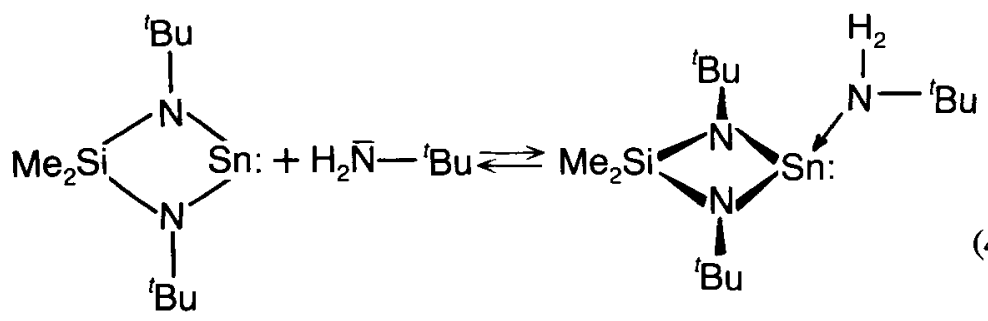


14 is in equilibrium with its components ${ }^{11}$; it is not stable and decomposes to the bis(amino)silane 4 and the already described products 9 or 11, depending on the molar ratios of 2 and tert-butylamine. ${ }^{3}$ A straightforward kinetic first-order law of decomposition of 14 cannot be demonstrated since the following reactions to the products seem to be of equal velocity. On the other hand, it can be shown that 9 decomposes by a first-order reaction into 2 and 6 , which is consistent with the appearance of the transient monomer $\left(\mathrm{SnN}-{ }^{t} \mathrm{Bu}\right)$ (Eq. (5)). ${ }^{3}$

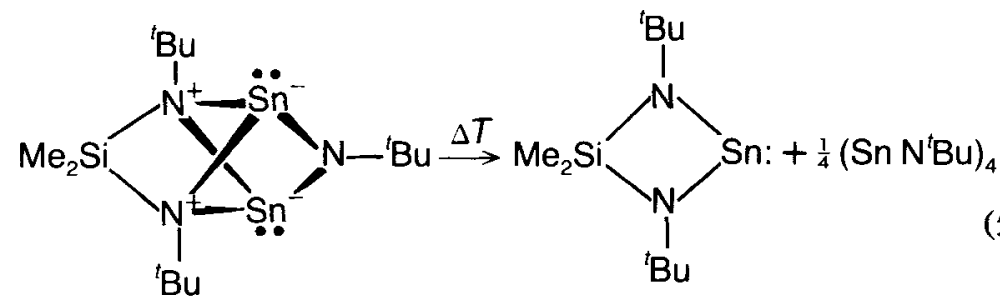

So far it seems reasonable to us to assume a hypothetical species $\{: \mathrm{GeN}-\mathrm{R}\},\{: \mathrm{SnN}-\mathrm{R}\}$ or $\{: \mathrm{SnO}\}$ in the reaction pathway. With this assumption, the pattern of different products may be explained quite easily, ${ }^{12}$ the formation of 9 starting with 2 and tert-butylamine (Eq. (3)) can be understood as a retroreaction of Eq. (5):

(1) In a first step the product of 2 and tert-butylamine 14 (Eq. (4)) is formed.

(2) In a second step 14 decomposes to the amine 4 and the intermediate $\left\{\mathrm{SnN}-{ }^{t} \mathrm{Bu}\right\}$ (Eq. (6))

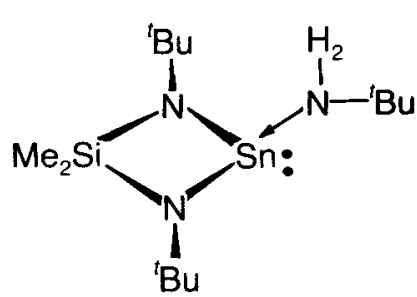

14

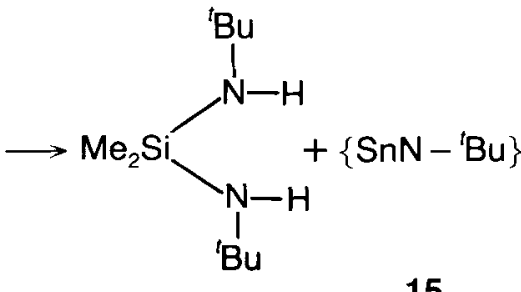

15 
(3) In the third step, the intermediate 15 is trapped by 2 , a reaction which can be understood as the collision of a compound, which unifies a double Lewis base with an acid (2), and a compound, which unifies a double Lewis acid with a base (15), when it is written in one of its mesomeric forms (see above):

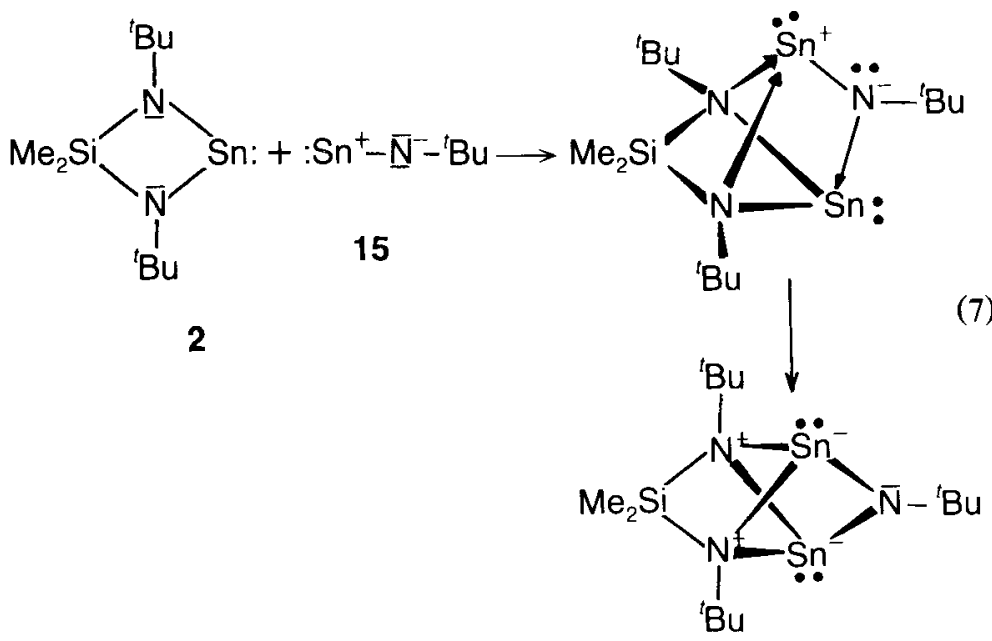

9

The formation of the other products of these reactions $5,6,7,8,10$, 11 can be described in a similar manner (cf. Ref. 12). The intrinsic problem nevertheless in these hypothetical formulations of reaction paths persists, as it cannot definitely be shown that the transient monomolecular species such as $\{\mathrm{SnO}\}$ or $\{\mathrm{SnN}-\mathrm{R}\}$ really occur.

\subsection{Trapping Reactions}

In order to obtain more information concerning the existence of the monomeric congeners of isocyanide or carbon monoxide respectively, we thought it useful to run the typical "formation reactions" of these hypothetical species in the presence of a trapping reagent other than 1 or 2 (see Eq. (7) for example). We have chosen compounds which chemically resemble 2 , as they have a central electronically unsaturated atom bonded to two Lewis bases: $\mathrm{Sn}\left(\mathrm{O}^{t} \mathrm{Bu}\right)_{2}(16)$ and $\mathrm{SnCl}_{2}$ (17). The two compounds differ from 2 in that they are dimeric 
(16) ${ }^{13,14}$ or poorly soluble in solvents such as benzene $\left(\mathrm{SnCl}_{2}\right)^{13}$ in which the reactions are performed.

As a result of these reactions easily isolable compounds have been obtained; these have been characterized, besides the usual techniques, by $x$-ray structure analysis in all three cases. ${ }^{13,15,16}$ As a common principle, all these compounds contain $\mathrm{SnN}-{ }^{t} \mathrm{Bu}$, but not in a ratio $1: 1$ with respect to the trapping reagent, but in a ratio $2: 1$ :

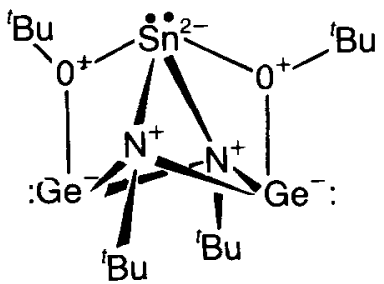

18

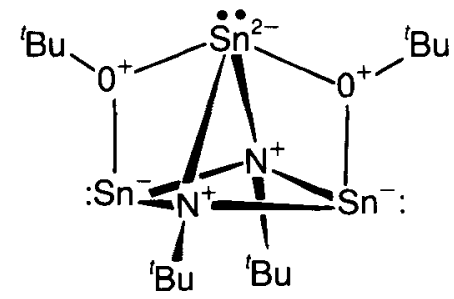

19

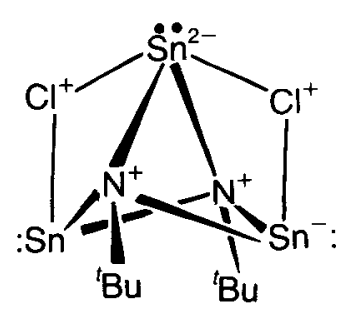

20

The formulas written for 18 and 19 reflect the structures quite well (although the formal charges should be viewed with caution), with the seven-atom central skeleton being built up of two trigonal bipyramids sharing one face. The formula of $\mathbf{2 0}$ is an oversimplification, as the structure in reality consists of a one-dimensional polymer, which arises from the intermolecular coordination of one of the two chloro-atoms to the two adjacent tin atoms. In this manner, all tin atoms adopt a fourfold coordination (Fig. 1). ${ }^{16}$

An important result of these experiments is that it is likely to assume at least a dimeric intermediate of $\left\{\mathrm{GeN}{ }^{t} \mathrm{Bu}\right\}$ or $\left\{\mathrm{SnN}^{t} \mathrm{Bu}\right\}$ as reacting species: 


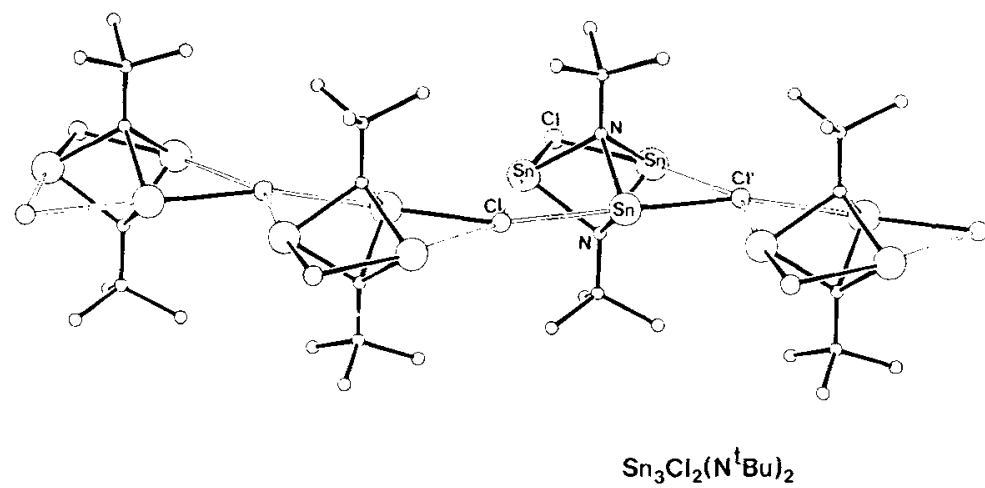

FIGURE 1 A section of the solid state structure of 20 showing the one-dimensional arrangement of the "molecules." Only the carbon atoms of the tert-butyl groups are drawn (small balls). A mirror plane divides the $\mathrm{Sn}_{3} \mathrm{~N}_{2}$-bipyramides into two equal sections, whereas a 2 -axis is responsible for the translation symmetry.<smiles>CCCCCCN1C(Br)=CC=CN1[GeH3]</smiles>

21<smiles>BrC1=CC=C[Se]N1CCc1ccccc1</smiles>

22

\section{RETROSYNTHETICAL ASPECTS: CAN SnCl ${ }^{+} \mathrm{BE}$ COORDINATED IN AN EQUAL MANNER LIKE SnN-t'Bu AND ITS OLIGOMERS?}

When we described, in Section 1.1, compounds of the general formula ElX (El $=$ element of group IV in oxidation state II, $X=$ a main group element with at least five valence electrons), we used three different mesomeric states to describe the possible electronic configuration. As we have shown, $\mathrm{X}$ can represent nitrogen or oxygen; but it should also be possible to introduce an element of the main group 
VII (the whole formula should have a positive charge). In this respect the following compounds are "isoelectronic":

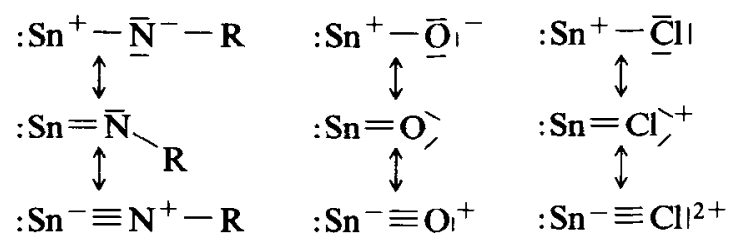

Taking these considerations into account, a compound resembling 8 and 9 should exist with the following formula:

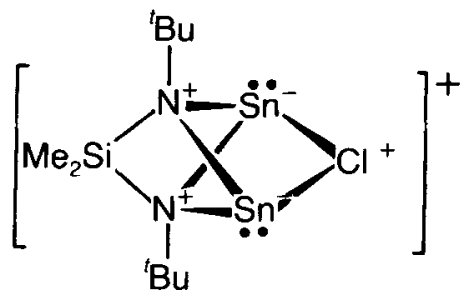

23

How can we prepare this hypothetical cation 23? Following the reasoning given in Section 2.2, we should treat $\mathrm{SnCl}_{2}$ with a Lewis acid, in order to remove a chloride anion, and "trap" the remaining $\mathrm{SnCl}^{+}$cation by the cyclic bisamino-stannylene 2 . This "retrosynthesis" works well, and as can be seen from Eq. (8), we do not need to add any strong Lewis acid, as $\mathrm{SnCl}_{2}$ acts as an acceptor of the $\mathrm{Cl}^{-}$anion. ${ }^{16}$

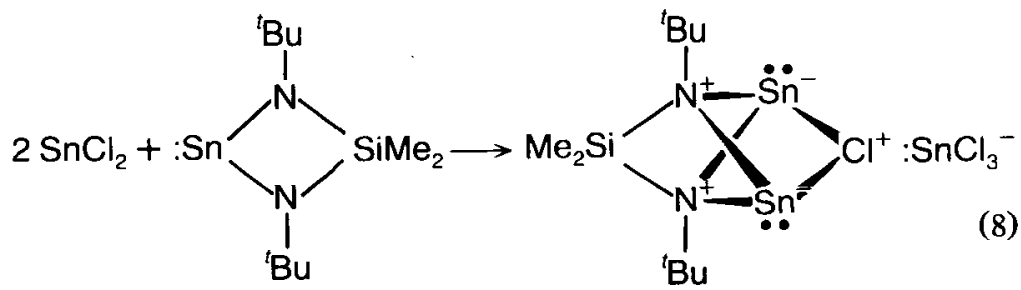


The compound 24 has been fully characterized by $x$-ray structure determination ${ }^{16}$ and it can be shown unambiguously that the cage unit within 24 is isostructural with the cage units which are present in 8 and 9 , respectively.

If we analyze these results more closely, it is clear that we cannot determine whether the $\mathrm{SnCl}^{+}$species is formed first and then trapped by 2 or (what is even more likely) whether an adduct of $\mathbf{2}$ and $\mathrm{SnCl}_{2}$ is formed first and then the chloride split off by attack of a second $\mathrm{SnCl}_{2}$ unit. We can conclude that even though our working hypothesis has led to the right compound 23, this does not establish that we have started from the correct hypothesis.

\section{CONCLUSIONS}

The general experience in chemistry, that a reaction pathway is difficult to establish, is also true for the formation of the compounds which we have discussed here and considered as being heavy congeners or "trapped congeners" of isocyanide and carbon monoxide. Even though we have not learned very much concerning the existence of monomeric species and their existence is still doubtful, we have acquired considerable experience in the construction of polymeric and cage-like compounds containing the heavier low-valent elements of group IV bound to oxygen, nitrogen, and chlorine. Application of the isoelectronic principle ${ }^{17}$ has again proved very fruitful. To use another example: the cage compound $\mathbf{2 6}$ can be prepared according to Eq. (9), ${ }^{18}$ the reacting thallium(I) alcoholate 25 in its monomeric form being isoelectronic with " $\mathrm{SnN}-{ }^{t} \mathrm{Bu}$."

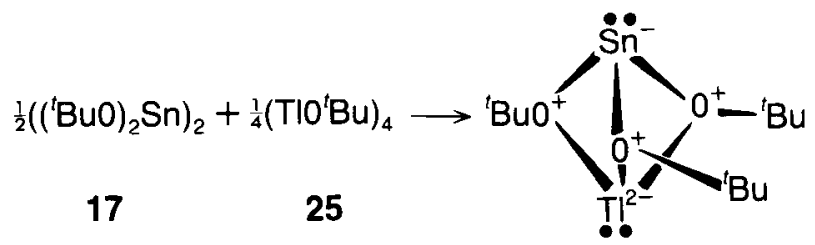

26

Further variations of this principle are, of course, possible.

On the other hand, our experience has led us to consider compounds such as 1,2 , and 3 as trifunctional Lewis acid-base systems. 
This model, which seems to work very well, may be expanded to include other compounds of low-valent elements, which are bound to electron-releasing atoms. We have found that $\left({ }^{t} \mathrm{BuO}\right)_{2} \mathrm{Ge}$ or $(t \mathrm{BuO})_{2} \mathrm{Sn}$ may be viewed in the same way, and even the chemically very different compound tin(II) chloride.

In Table I six different compounds are arranged in a matrix-like way. Each compound within the frame is built of similar structural units, which are given at the head of the columns and rows, respec-

Table I

Common structural elements in different polycycles, cages, and inorganic solids ( $R$ $={ }^{\prime} \mathrm{Bu}$ ). $\mathrm{n}$ denotes the number of times a structural element, which is placed at the head of a column or row, is present in the compound. The formal charges of the elements have been omitted; for these the reader is referred to the text.

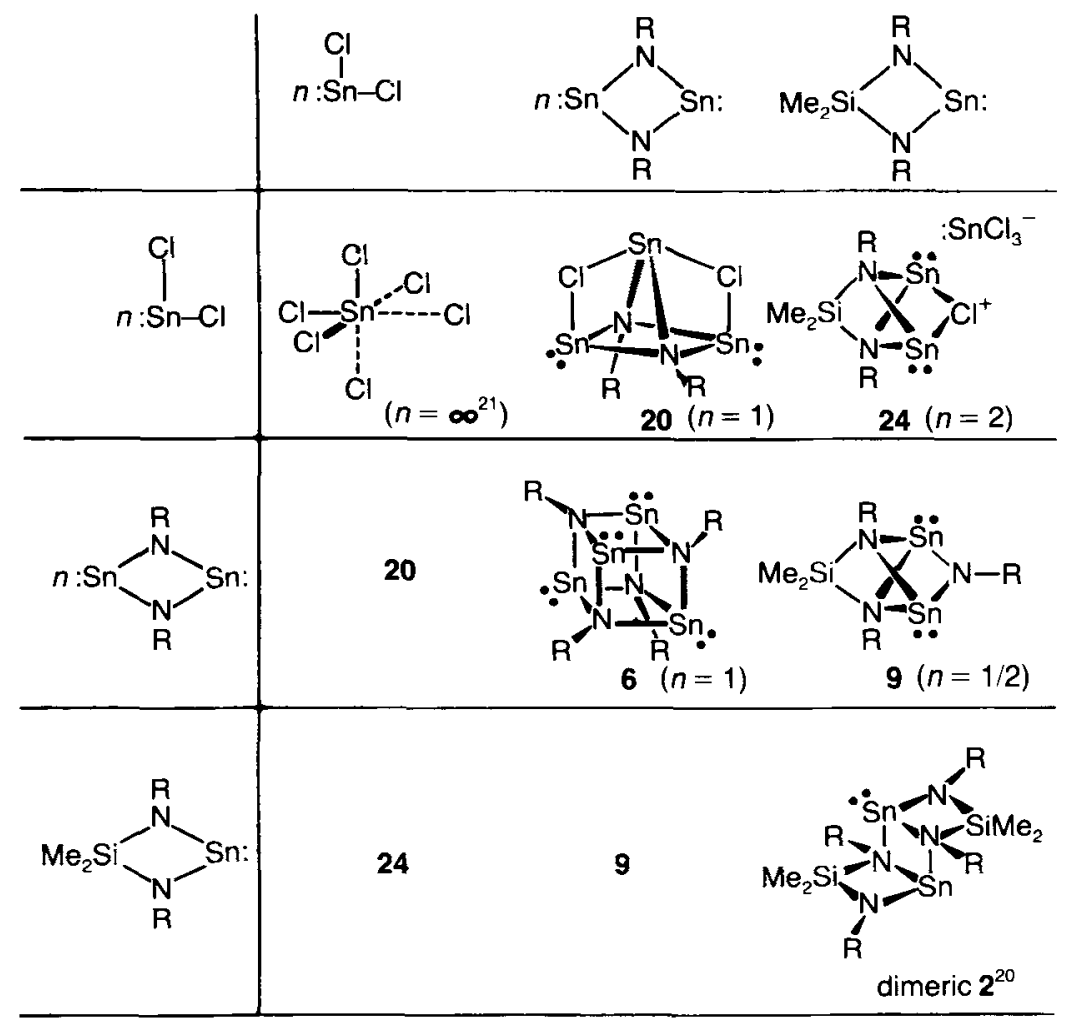


tively. As can be easily seen, a $1: 1$ correspondence of the structural elements forming the polycycle is not always found; instead $2: 1$ ratios also exist. This purely structural procedure may also be expanded to chemical reactions in another way: one may first go to the top of the rows and columns and interpret the point of intersection as a product of the reaction between these two compounds. This is true for the formation of the dimeric 2 from monomeric species, as we have been able to show. ${ }^{19,20}$ Although we are tempted to view the formation of the other compounds in Table $I$ in the same manner, we are not sure whether this is appropriate.

\author{
M. VEITH \\ Anorganische Chemie, \\ Universität des Saarlandes, \\ Im Stadtwald, \\ D-6600 Saarbrïcken, \\ Federal Republic of Germany
}

\title{
References
}

1. A. F. Wells, Structural Inorganic Chemistry, Fourth Edition (Clarendon, Oxford, 1975).

2. L. Brewer and K. Edwards, J. Phys. Chem. 58, 216 (1955).

3. M. Veith, M.-L. Sommer and D. Jäger, Chem. Ber. 112, 2581 (1979).

4. M. Veith and M. Grosser, Z. Naturforsch. B 37, 1375 (1982).

5. M. Veith, Angew. Chem. 87, 287 (1975); Angew. Chem. Int. Ed. Engl. 14, 263 (1975).

6. M. Veith, Chem. Ber. 111, 2536 (1978).

7. M. Veith and G. Schlemmer, Chem. Ber. 115, 2141 (1982).

8. M. Veith and O. Recktenwald, Z. Naturforsch. B 38, 1054 (1983).

9. M. Veith, Z. Naturforsch. B 35, 20 (1980).

10. M. Veith and H. Lange, Angew. Chem. 92, 408 (1980); Angew. Chem. Int. Ed. Engl. 19, 401 (1980).

11. M. Veith and G. Schlemmer, Z. Anorg. Allg. Chem. 497, 157 (1983).

12. M. Veith and O. Recktenwald, Top. Curr. Chem. 104, 1 (1982).

13. W. Frank, Thesis, University of Braunschweig, FRG, 1985.

14. M. Veith and F. Töllner, J. Organomet. Chem. 246, 219 (1983).

15. M. Veith and W. Frank, Angew. Chem. 96, 163 (1984); Angew Chem. Int. Ed. Engl. 23, 158 (1984).

16. V. Huch, Thesis, University of Braunschweig, FRG, 1984.

17. H. Schmidbaur, Fortschr. Chem. Forsch. (Top. Curr. Chem.) 13, 167 (1969).

18. M. Veith and R. Rösler, Angew. Chem. 94, 867 (1982); Angew. Chem. Int. Ed. Engl. 21, 858 (1982).

19. M. Veith, Z. Naturforsch, B 33, 1 (1978).

20. M. Veith, Z. Naturforsch. B 33, 7 (1978).

21. J. M. van den Berg, Acta Crystallogr. 14, 1002 (1961). 